\title{
Vaginal Undifferentiated Sarcoma
}

National Cancer Institute

\section{Source}

National Cancer Institute. Vaginal Undifferentiated Sarcoma. NCI Thesaurus. Code C40272.

A high grade infiltrating sarcoma that arises from the vagina. It is characterized by the presence of malignant small spindle cells with scant cytoplasm. 